\title{
Effects of one-year anti-TNF- $\alpha$ therapy on biomarkers of angiogenesis and functional vascular parameters in arthritides
}

Emese Balogh ${ }^{1,5}$, Edit Végh ${ }^{1}$, György Kerekes ${ }^{2}$, Anita Pusztai ${ }^{1}$, Attila Hamar ${ }^{1}$, Katalin Hodosi ${ }^{1}$, Szilvia Szamosi ${ }^{1}$, Andrea Váncsa ${ }^{1}$, Péter Csomor ${ }^{1}$, Levente Bodoki ${ }^{1}$, Lilla Pogácsás ${ }^{1}$, Fruzsina Balázss ${ }^{1}$, Ildikó Tar ${ }^{4}$, Jennifer McCormick, Monika Biniecka ${ }^{5}$, Ursula Fearon ${ }^{6}$, Karin Lundberg $^{7}$, Nastya Kharlamova ${ }^{7}$, Sándor Szántó ${ }^{1,3}$, Gabriella Szúcs ${ }^{1}$, Zoltán Nagy ${ }^{1}$, Douglas J Veale ${ }^{5}$ and Zoltán Szekanecz ${ }^{1 *}$

${ }^{1}$ Departments of Rheumatology, University of Debrecen, Hungary

${ }^{2}$ Departments of Angiology, University of Debrecen, Hungary

${ }^{3}$ Department of Sports Medicine, University of Debrecen, Hungary

${ }^{4}$ Department of Periodontology, University of Debrecen, Hungary

${ }^{5}$ Centre for Arthritis and Rheumatic Diseases, St. Vincent's University St. Vincent's University Hospital, Ireland

${ }^{6}$ Molecular Rheumatology, Trinity Biomedical Sciences Institute, Ireland

${ }^{7}$ Division of Rheumatology, Department of Medicine Solna, Karolinska Institutet, Sweden

\begin{abstract}
Background: Increased cardiovascular (CV) morbidity and mortality and abundant angiogenesis have been associated with rheumatoid arthritis (RA) and ankylosing spondylitis (AS). Biologics may influence both vascular function and angiogenesis. Here, vascular function, markers of atherosclerosis angiogenesis and the effects of anti-TNF therapy on these biomarkers were assessed arthritides.

Patients and methods: Altogether 53 arthritis patients including 36 RA patients treated with etanercept (ETN) or certolizumab pegol (CZP) and 17 AS patients treated with ETN were included in a 12-month follow-up study. Angiogenesis markers including vascular endothelial (VEGF) and platelet-derived growth factor (PDGF-BB), angiopoetin 1 and 2 (Ang1, Ang2) and thrombospondin 1 (TSP-1) were assessed by ELISA. Anti-CCP and anti-citrullinated enolase peptide (CEP) antibodies were also determined by ELISA. Flow-mediated vasodilation (FMD), common carotid intima-media thickness (ccIMT) and pulse-wave velocity (PWV) were assessed by ultrasound. All assessments were performed at baseline, as well as 6 and 12 months after treatment initiation.
\end{abstract}

Results: One-year anti-TNF therapy significantly decreased VEGF, PDGF-BB and Ang2 serum levels. In uni- and multivariate analyses, PDGF-BB levels correlated with smoking, disease duration and ccIMT. Moreover, Ang1 correlated with CRP, Ang2 with disease duration, CRP and positive CV history. Finally, TSP-1 levels correlated with disease duration, anti-CCP, anti-CEP and ccIMT.

Conclusions: In our arthritis cohort, the levels of angiogenic markers correlated with disease duration, CRP, ACPA and ccIMT. Anti-TNF therapy attenuated the production of angiogenic markers in these arthritides. Some angiogenic mediators may be used as surrogate biomarkers that link angiogenesis, inflammation and atherosclerosis in arthritides.

\begin{abstract}
Abbreviations: ACPA: anti-citrullinated protein antibody; Ang: angiopoietin; AS: ankylosing spondylitis; BASDAI: Bath Ankylosing Spondylitis Disease Activity Index; ccIMT: common carotid intimamedia thickness; CCP: cyclic citrullinated peptide; CEP: citrullinated enolase peptide; CRP: C-reactive protein; CTGF: connective tissue growth factor; CV: cardiovascular; CZP: certolizumab pegol; DAS28: 28-jopint disease activity scale; DMARD: disease-modifying antirheumatic drug; ECG: electrocardiogram; ECM: extracellular matrix; ELISA: enzyme-linked immunosorbent assay; ETN: etanercept; FMD: flow-mediated vasodilation; PDGF-BB: platelet-derived growth factor BB isoform; PWV: pulse-wave velocity; RA: rheumatoid arthritis; TGF: transforming growth factor; Tie: receptor tyrosine kinase; TNF: tumors necrosis factor; TSP: thrombospondin; VEGF: vascular endothelial growth factor.
\end{abstract}

\section{Background}

Accelerated, inflammatory atherosclerosis leading to increased cardiovascular (CV) morbidity and mortality has also been observed in rheumatoid arthritis (RA) and ankylosing spondylitis (AS) [1-4]. Vascular abnormalities can be observed early, even in patients without

*Correspondence to: Zoltán Szekanecz, University of Debrecen Faculty of Medicine, Department of Rheumatology, Nagyerdei str 98, Debrecen, 4032, Hungary, Tel/Fax: +36-52-255-091; Email: szekanecz.zoltan@med.unideb.hu

Key words: rheumatoid arthritis, angiogenesis, atherosclerosis, anti-TNF therapy, biomarkers

Received: September 16, 2019; Accepted: September 27, 2019; Published: October 02, 2019 
clinical CV disease [1,2]. Ultrasound-based imaging modalities are able to detect preclinical vascular pathophysiology [5]. Endothelial dysfunction, manifest atherosclerosis and increased arterial stiffness are indicated by abnormal endothelium-dependent, flow-mediated vasodilation (FMD), common carotid intima-media thickness (ccIMT) and arterial pulse-wave velocity (PWV), respectively [2,3,5-11]. These preclinical abnormalities predict the development of subsequent $\mathrm{CV}$ events in arthritides [5,11].

RA and AS have been associated with the perpetuation of endothelial activation and angiogenesis in the synovial tissue [12-15]. Several angiogenic mediators promote synovial neovascularization [12-16]. The hypoxia-vascular endothelial growth factor (VEGF)angiopoetin 1 (Ang1) axis plays an essential role in orchestrating arthritis-associated angiogenesis. Ang2 acts as a partial agonist to the receptor tyrosine kinase-2 (Tie2) and by competing with Ang1 for Tie2 binding [16-18]. Other angiogenic growth factors include platelet-derived growth factor (PDGF). PDGF may stimulate angiogenesis both in vitro and in vivo $[12,15]$. Thrombospondin 1 (TSP-1) is an extracellular matrix (ECM) protein also expressed by inflammatory cells. It regulates angiogenesis in arthritis, by upstream signalling of the transforming growth factor $\beta$ (TGF- $\beta$ )-connective tissue growth factor (CTGF) axis [19, 20]. VEGF, Ang1, Ang2, PDGF and TSP- 1 are readily detectable in the sera and synovial fluids of arthritis patients and they may serve as potential biomarkers of inflammatory angiogenesis $[12,15]$. Synovial vascularity determined by power Doppler ultrasound was correlated with VEGF, Ang1 and Ang2 levels [21]. VEGF may serve as a marker of angiogenesis, as well as disease activity $[13,15]$. Numerous compounds, among others several conventional and targeted disease-modifying antirheumatic drugs (DMARDs) and VEGF inhibitors also suppress synovial neovascularization $[18,22,23]$.

In order to link the two above-mentioned processes, angiogenesis has been implicated in the pathogenesis of atherosclerosis [15,24]. Angiogenic factors and new blood vessels indicate an increased risk for plaque rupture. The final event of tissue degradation is mediated by ECM proteases in the pathology of atherosclerosis, as well as joint destruction $[4,15,24]$. Moreover, systemic inflammation is the major driver of both inflammatory angiogenesis and atherosclerosis $[1,2,4,12,15]$. Tumour necrosis factor $\alpha$ (TNF- $\alpha$ ) is highly involved in the pathogenesis of RA-related angiogenesis and atherosclerosis $[12,14,25]$. The control of inflammation by targeted therapies including TNF- $\alpha$ inhibitors, may dampen these two processes [23,26,27]. AntiTNF biologics may improve vascular pathophysiology $[1,27]$ and may also reduce the production of some angiogenic markers [27-29]. As periodontitis and anti-citrullinated enolase peptides (CEP) have been implicated in RA [30] and AS [31], as well as atherosclerosis [32], we also performed an oral examination and anti-CEP testing.

In this study, we wished to determine the effects of one-year antiTNF therapy on the production of angiogenic biomarkers. Our primary hypothesis was that biologic treatment suppressed the production of these markers. In addition, we also determined the release of angiogenic markers in relation to functional vascular parameters, oral health and some other clinical parameters in order to understand the complexity of angiogenesis regulation.

\section{Methods}

\section{Patients}

Fifty-three patients with inflammatory arthritis (36 RA and 17 AS) were enrolled in the study. Patient characteristics are seen in Table 1.
The cohort included 34 women and 19 men with mean age of $52.0 \pm$ 12.1 (range: $24-83$ ) years. Mean disease duration was $8.5 \pm 7.9$ (range: 1-44) years. Patients with active disease were recruited prior to initiating a biological therapy. All patients were biologic-naïve, started on an antiTNF therapy at baseline and received the same biological treatment at one year. Among the 36 RA patients, 20 received etanercept (ETN) 50 $\mathrm{mg} /$ week subcutaneous (SC) and 16 received certolizumab pegol (CZP) ( $400 \mathrm{mg}$ at 0,2 and 4 weeks, and thereafter $200 \mathrm{mg}$ twice weekly SC). All 17 AS patients received ETN $50 \mathrm{mg} /$ week SC.

The study was approved by the Hungarian Scientific Research Council Ethical Committee (approval No. 14804-2/2011/EKU). Written informed consent was obtained from each patient and assessments were carried out according to the Declaration of Helsinki. No individual patient data are reported.

\section{Clinical assessment}

First, detailed medical history was taken. We inquired for current smoking, history of CV disease, periodontitis and tooth loss during the last year prior to the start of this study by a questionnaire (Table 1). Further clinical assessments including physical examination were performed at baseline, and after 3, 6 and 12 months of therapy. At baseline RA patients had a mean DAS28 of $5.00 \pm 0.86$, while AS patients exerted mean BASDAI of $5.79 \pm 1.19$ (Table 1 ).

All patients' dental condition was recorded by a dentist (IT). The number of missing teeth was counted. Based on periodontal charting according to current classification [33], the presence of periodontitis was recorded.

\section{Laboratory measurements}

Serum high sensitivity $\mathrm{C}$ reactive protein (hsCRP; normal: $\leq 5 \mathrm{mg} / \mathrm{l}$ ) and IgM rheumatoid factor (RF; normal: $\leq 50 \mathrm{IU} / \mathrm{ml}$ ) were measured by quantitative nephelometry (Cobas Mira Plus-Roche), using CRP and RF reagents (both Dialab). ACPA (anti-CCP) autoantibodies were detected in serum samples using a second generation Immunoscan-RA CCP2 ELISA test (Euro Diagnostica; normal: $\leq 25 \mathrm{IU} / \mathrm{ml}$ ). The assay was performed according to the manufacturer's instructions.

Among serum biomarkers of angiogenesis, VEGF (V-Plex, Meso Scale Diagnostics; pg/ml), PDGF-BB (DuoSet ELISA, R\&D Systems; pg/ml), Ang1 (DuoSet ELISA, R\&D Systems; pg/ml), Ang2 (QuantiKine ELISA, R\&D Systems; pg/ml) and TSP-1 (DuoSet ELISA,

Table 1. Patient characteristics

\begin{tabular}{|l|c|c|c|}
\hline \multicolumn{1}{|c|}{ RA } & AS & Total \\
\hline $\mathrm{n}$ & 36 & 17 & 53 \\
\hline female:male & $31: 5$ & $3: 14$ & $34: 19$ \\
\hline age (mean \pm SEM)(range), years & $\begin{array}{c}55.9 \pm 9.8 \\
(35-83)\end{array}$ & $\begin{array}{c}43.6 \pm 12.4 \\
(24-72)\end{array}$ & $\begin{array}{c}52.0 \pm 12.1 \\
(24-83)\end{array}$ \\
\hline $\begin{array}{l}\text { disease duration (mean } \pm \text { SEM) } \\
\text { (range), years }\end{array}$ & $9.1 \pm 8.3(1-44)$ & $7.2 \pm 7.0(1-26)$ & $8.5 \pm 7.9(1-44)$ \\
\hline smoking (current) & 7 & 7 & 14 \\
\hline positive CV history & 8 & 1 & 9 \\
\hline periodontitis (current) & 10 & 5 & 15 \\
\hline tooth loss (current) & 14 & 7 & 21 \\
\hline RF positivity, $\mathrm{n}(\%)$ & $26(72)$ & - & - \\
\hline ACPA positivity, $\mathrm{n}(\%)$ & $21(58)$ & - & - \\
\hline DAS28 (baseline) (mean \pm SEM) & $5.00 \pm 0.86$ & - & - \\
\hline BASDAI (baseline) (mean \pm SEM) & - & $5.79 \pm 1.19$ & - \\
\hline Treatment (ETN, CZP) & 20 ETN, 16 & 17 ETN & 37 ETN, 16 CZP \\
\hline
\end{tabular}


$\mathrm{R} \& \mathrm{D}$ Systems; $\mathrm{ng} / \mathrm{ml}$ ) levels were determined by ELISA at baseline, as well as after 6 and 12 months of anti-TNF therapy.

\section{Determination of anti-CEP-1 levels}

Anti-CEP-1 IgG was measured in the serum samples using an inhouse peptide ELISA, as previously described [30]. Anti-CEP-1 IgG levels are presented as $\mathrm{AU} / \mathrm{ml}$, based on a standard curve. The cut-off for „positivity” and „negativity” was $3.7 \mathrm{AU} / \mathrm{ml}$.

\section{Assessment of vascular physiology by ultrasound}

Brachial artery FMD was assessed as described before [6,7,34]. In brief, ultrasound examination was performed on the right arm using 10 $\mathrm{MHz}$ linear array transducer (ultrasound system: HP Sonos 5500) by a single trained sonographer after 30 minutes resting in a temperaturecontrolled room (basal value for FMD). A B-mode longitudinal section was obtained of the brachial artery above the antecubital fossa. In order to assess FMD, reactive hyperaemia was induced by release of a pneumatic cuff around the forearm inflated to suprasystolic pressure for 4.5 minutes. After deflation the maximal flow velocity and the arterial diameter was 90 seconds long continuously recorded. Flow velocities, the baseline diameter, as well as FMD were ECG gated and detected offline. FMD values were expressed as \% change from baseline (resting) value (FMD\%). In our previous work, we divided RA patients into "high (normal) FMD" and "low (impaired) FMD" subsets by defining a cutoff value of 5\% [34]. We used the same cut-off in the present studies.

The ccIMT measurements were carried out as described before $[6,8,34]$. Briefly, a duplex ultrasound system (HP Sonos 5500, $10 \mathrm{MHz}$ linear array transducer) was used to assess the common carotid arteries by a single observer. Longitudinal high-resolution B-mode ultrasound scan were employed over both right and left common carotid arteries and were R-synchronized and recorded. The offline measurements were performed $1 \mathrm{~cm}$ proximal to the carotid bulb in the far wall. ccIMT was defined as the distance between the first and second echogenic lines from the lumen taking the average of 10 measurements on both sides. ccIMT values were expressed in mm. In our previous work, we divided RA patients into "high (increased) ccIMT" and "low (normal) ccIMT" subsets by using a cut-off value of $0.65 \mathrm{~mm}$ [34]. We used the same cutoff in the present studies.

With respect to arterial stiffness, PWV was calculated automatically by a TensioClinic arteriograph system (Tensiomed Ltd, Budapest, Hungary) as the quotient of the distance between the jugular fossa and symphysis as described before [6,9]. If an artery is elastic, PWV is low. With decreased arterial elasticity, PWV rises. The arteriograph assesses this parameter from the oscillometric data obtained from the $35 \mathrm{mmHg}$ suprasystolic pressure of the brachial artery. In order to obtain reproducible results, the patient had to rest in a supine position for at least 10 minutes before the assessment in a quiet room. PWV is expressed in $\mathrm{m} / \mathrm{s}$. Based on our previous experience [6] we used a cutoff value of $8 \mathrm{~m} / \mathrm{s}$, where $\mathrm{PWV} \leq 8 \mathrm{~m} / \mathrm{s}$ and $\mathrm{PWV}>8 \mathrm{~m} / \mathrm{s}$ indicated "low (normal)" and "high (increased)" PWV, respectively.

\section{Statistical analysis}

Statistical analysis was performed using SPSS version 22.0 (IBM) software. Data are expressed as the mean \pm SD for continuous variables and percentages for categorical variables. Continuous variables were evaluated by paired two-tailed t-test and Wilcoxon test. Nominal variables were compared between groups using the chi-squared or Fisher's exact test, as appropriate. Correlations were determined by Spearman's analysis. Univariate and multiple regression analysis using the stepwise method was applied to investigate independent associations between angiogenic biomarkers (dependent variables) and other clinical, laboratory and imaging parameters (independent variables). The $\beta$ standardized linear coefficients showing linear correlations between two parameters were determined. The B $(+95 \%$ CI) regression coefficient indicated independent associations between dependent and independent variables during changes. Repeated measures analysis of variance (RM-ANOVA) was performed in order to determine the additional effects of multiple parameters on changes of vascular imaging markers between baseline and 12 months. The dependent variables were VEGF, PDGF-BB, Ang1, Ang2 and TSP1. Partial $\eta^{2}$ is given as indicator of effect size, with values of 0.01 suggesting small, 0.06 medium and 0.14 large effects. In all analyses, $\mathrm{P}$ values $<0.05$ were considered significant.

\section{Results}

\section{Clinical response to anti-TNF therapy in inflammatory arthritides}

Although we used a mixed cohort of RA and AS patients in our present study, as RA and AS disease activity are assessed by different methods, we first determined the efficacy of biologic therapy in the two diseases. In RA $(n=36)$, anti-TNF treatment resulted in significant decrease in DAS28 after 12 months of treatment (3.02 \pm 0.96$)$ compared to baseline (5.00 $\pm 0.86 ; \mathrm{p}<0.001)$. In AS ( $\mathrm{n}=17)$, BASDAI significantly decreased from $5.79 \pm 1.19$ at baseline to $1.86 \pm 1.04$ after 12 months $(\mathrm{p}<0.001)$.

\section{Effects of TNF inhibition of the levels of angiogenic biomarkers}

In the mixed cohort of 53 arthritis patients, VEGF levels showed non-significant reduction from a baseline of $267.9 \pm 123.3 \mathrm{pg} / \mathrm{ml}$ to $239.8 \pm 116.3 \mathrm{pg} / \mathrm{ml}(\mathrm{p}=0.082)$ at 6 months followed by significant decrease to $220.9 \pm 120.7 \mathrm{pg} / \mathrm{ml}$ at 12 months $(\mathrm{p}=0.007)$ of treatment. (Figure 1A). Serum PDGF-BB levels significantly dropped after 6 months $(6579.4 \pm 3819.2 \mathrm{pg} / \mathrm{ml} ; \mathrm{p}=0.015)$ with even further reduction at 12 months $(6020.4 \pm 3216.1 \mathrm{pg} / \mathrm{ml} ; \mathrm{p}=0.005)$ compared to baseline $(8187.4 \pm 6282.0 \mathrm{pg} / \mathrm{ml})$ (Figure 1B). Serum Ang2 concentrations significantly decreased after 6 months $(2473.7 \pm 1136.1 \mathrm{pg} / \mathrm{ml} ; \mathrm{p}=0.024)$ and showed non-significant reduction at 12 months $(2537.2 \pm 1156.1$ $\mathrm{pg} / \mathrm{ml}) ; \mathrm{p}=0.081)$ vs baseline $(2790.0 \pm 1381.1 \mathrm{pg} / \mathrm{ml})$ (Figure 1C). Serum Ang1 and TSP-1 levels did not change overtime during antiTNF therapy.

\section{Correlations of angiogenic biomarkers with other parameters}

In the simple Spearman's correlation analysis, PDGF-BB levels at 12 months of treatment $(\mathrm{R}=0.436, \mathrm{p}=0.014)$, Ang2 at baseline $(\mathrm{R}=0.555, \mathrm{p}=0.001)$ and at 12 months $(\mathrm{R}=0.452, \mathrm{p}=0.011)$ correlated with disease duration. Baseline CRP showed correlation with baseline Ang1 $(\mathrm{R}=0.370, \mathrm{p}=0.041)$, as well as baseline $(\mathrm{R}=0.419, \mathrm{p}=0.019)$ and post-treatment Ang2 levels $(\mathrm{R}=0.406, \mathrm{p}=0.023)$. Post-treatment CRP correlated with pre- and post-treatment Ang2 $(\mathrm{p}<0.05)$. Baseline antiCCP $(\mathrm{R}=0.548, \mathrm{p}=0.018)$ and anti-CEP levels $(\mathrm{R}=0.625, \mathrm{p}=0.007)$ correlated with baseline TSP-1. Finally, baseline ccIMT exerted correlations with baseline PDGF-BB $(\mathrm{R}=0.459, \mathrm{p}=0.009)$ and baseline TSP-1 $(\mathrm{R}=0.406, \mathrm{p}=0.024)$ (Table 2$)$. When current smokers $(\mathrm{n}=14)$ and non-smokers $(n=39)$ were compared (Table 1$)$, PDGF-BB levels at 12 months of treatment were significantly higher in smokers $(8903.2 \pm 5084.1 \mathrm{pg} / \mathrm{ml})$ compared to non-smokers $(4866.2 \pm 1895.8$ $\mathrm{pg} / \mathrm{ml} ; \mathrm{p}=0.01$ ). Current clinical periodontitis or tooth loss was not associated with elevated angiogenic marker levels. 
A

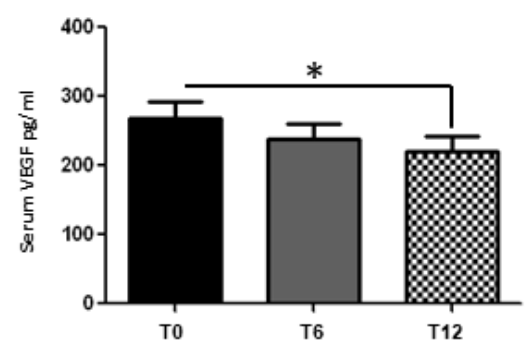

B

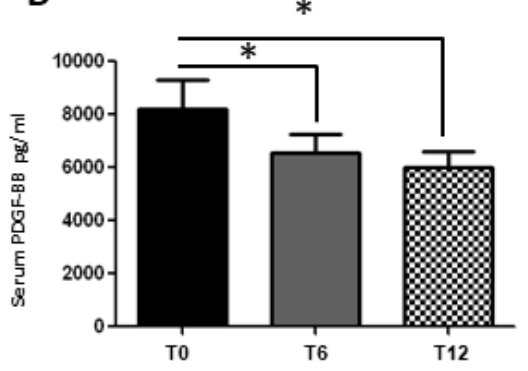

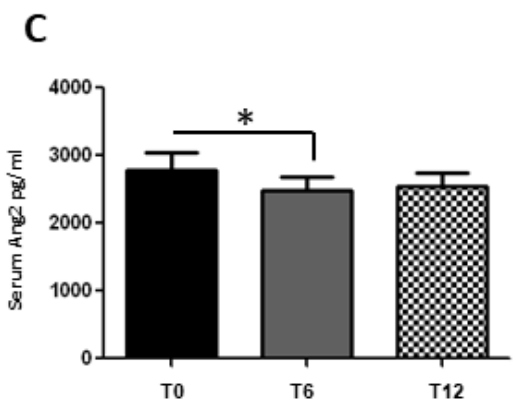

Figure 1. Effects of one-year anti-TNF therapy on serum levels of VEGF (1A), PDGF-BB (1B) and Ang2 (1C). Measurements were performed at baseline (T0), after 68 T6) and 12 months $8 \mathrm{~T} 12)$ of treatment. Asterisks indicate significant changes $(\mathrm{p}<0.05)$

Table 2. Significant correlations between angiogenic marker levels and other parameters

\begin{tabular}{|c|c|c|c|c|c|c|c|}
\hline & disease duration & CRP-0 & CRP-6 & CRP-12 & IMT-0 & IMT-12 & FMD-6 \\
\hline PDGF-BB-0 & NS & NS & NS & NS & $\begin{array}{l}\mathrm{R}=0.459 \\
\mathrm{p}=0.009\end{array}$ & NS & NS \\
\hline PDGF-BB-6 & NS & NS & NS & NS & $\begin{array}{l}\mathrm{R}=0.364 \\
\mathrm{p}=0.044\end{array}$ & NS & NS \\
\hline PDGF-BB-12 & $\begin{array}{l}\mathrm{R}=0.436 \\
\mathrm{p}=0.014\end{array}$ & NS & NS & NS & NS & NS & NS \\
\hline Ang1-0 & NS & $\begin{array}{l}\mathrm{R}=0.370 \\
\mathrm{p}=0.041\end{array}$ & NS & NS & NS & $\begin{array}{l}\mathrm{R}=0.372 \\
\mathrm{p}=0.039\end{array}$ & NS \\
\hline Ang2-0 & $\begin{array}{l}\mathrm{R}=0.555 \\
\mathrm{p}=0.001\end{array}$ & $\begin{array}{l}\mathrm{R}=0.419 \\
\mathrm{p}=0.019\end{array}$ & NS & $\begin{array}{l}\mathrm{R}=0.416 \\
\mathrm{p}=0.020\end{array}$ & NS & NS & NS \\
\hline Ang2-6 & $\begin{array}{l}\mathrm{R}=0.434 \\
\mathrm{p}=0.015\end{array}$ & $\begin{array}{l}\mathrm{R}=0.428 \\
\mathrm{p}=0.016\end{array}$ & NS & $\begin{array}{l}\mathrm{R}=0.487 \\
\mathrm{p}=0.005\end{array}$ & NS & NS & NS \\
\hline Ang2-12 & $\begin{array}{l}\mathrm{R}=0.452 \\
\mathrm{p}=0.011\end{array}$ & $\begin{array}{l}\mathrm{R}=0.406 \\
\mathrm{p}=0.023\end{array}$ & NS & $\begin{array}{l}\mathrm{R}=0.411 \\
\mathrm{p}=0.022\end{array}$ & NS & NS & NS \\
\hline TSP1-0 & NS & NS & $\begin{array}{l}\mathrm{R}=0.368 \\
\mathrm{p}=0.042\end{array}$ & NS & $\begin{array}{l}\mathrm{R}=0.406 \\
\mathrm{p}=0.024\end{array}$ & NS & NS \\
\hline TSP1-12 & NS & NS & $\begin{array}{l}\mathrm{R}=0.368 \\
\mathrm{p}=0.042\end{array}$ & NS & $\begin{array}{l}\mathrm{R}=0.406 \\
\mathrm{p}=0.024\end{array}$ & NS & $\begin{array}{l}\mathrm{R}=0.408 \\
\mathrm{p}=0.023\end{array}$ \\
\hline
\end{tabular}

NS, non-significant. See text for other abbreviations and explanations.

Results of the univariate and multivariate analyses are indicated in Table 3. According to the univariate analysis, PDGF-BB levels at baseline correlated with baseline ccIMT, while PDGF-BB after 12 months of treatment correlated with disease duration and current smoking status $(\mathrm{p}<0.05)$. Ang1 at baseline correlated with baseline CRP $(\mathrm{p}<0.05)$. Ang2 at baseline showed correlation with disease duration, the positive history of CV disease, as well as baseline CRP, while posttreatment Ang2 correlated with disease duration, as well as baseline and 12-month CRP $(\mathrm{p}<0.05)$. Finally, TSP-1 levels at baseline correlated with disease duration, as well as baseline ccIMT and CEP levels $(\mathrm{p}<0.05)$ (Table 3). There were no correlations between any angiogenic markers and FMD or PWV.
As suggested by the multivariate analysis, smoking was an independent predictor of post-treatment PDGF-BB levels $(\mathrm{p}=0.006)$. Disease duration determined baseline Ang2 ( $\mathrm{p}<0.001)$, 12-month Ang2 ( $\mathrm{p}=0.004)$ and baseline TSP-1 ( $\mathrm{p}=0.028)$. Baseline CRP was an independent predictor of baseline Ang2 $(\mathrm{p}=0.004)$. Finally, baseline CEP determined baseline TSP-1 levels $(\mathrm{p}=0.002)$ (Table 3$)$.

Finally, RM-ANOVA analysis was performed in order to assess the determinants of 12-month changes in angiogenic markers as dependent variables. In the full cohort $(\mathrm{p}=0.006)$ and AS patients $(\mathrm{p}=0.034)$ antiTNF treatment itself determined the changes of VEGF. In addition, treatment exerted combined effects with age $(\mathrm{p}=0.043)$ on changes in 
VEGF in AS only (Table 4). With respect to PDGF-BB, TNF inhibition alone $(p=0.009)$, as well as in combination with treatment responsiveness $(\mathrm{p}=0.038)$, age $(\mathrm{p}=0.014)$ and $\mathrm{ccIMT}(\mathrm{p}=0.014)$ determined 12 -month changes in this biomarker. Biologic treatment alone $(p=0.011)$ or in combination with a positive CV history $(\mathrm{p}=0.017)$ determined changes in PDGF-BB in RA only and AS only, respectively (Table 4). In the full cohort, anti-TNF therapy in combination with age at diagnosis $(\mathrm{p}=0.013)$ and with CRP $(\mathrm{p}=0.033)$ determined 12-month changes in Ang1. In AS, treatment and age at diagnosis exerted a combined effect on Ang1 changes ( $\mathrm{p}=0.010$ ) (Table 4). Anti-TNF therapy itself $(\mathrm{p}=0.039)$ determined Ang2 changes in the full cohort, while TNF inhibition with baseline CEP exerted a combined effect on changes in this angiogenic marker $(\mathrm{p}=0.035)$ (Table 4). Finally, treatment together with positive CV history determined one-year changes of TSP-1 in the full cohort ( $\mathrm{p}=0.041)$, in RA ( $\mathrm{p}=0.035)$ and in AS ( $\mathrm{p}=0.044)$ (Table 4).

\section{Discussion}

Synovial angiogenesis is a well-recognized primary event in perpetuation of local inflammation in inflammatory arthritis. This neovascularization process is associated with the abundant production of pro-inflammatory molecules, most of which has pro-angiogenic effects, hence further triggering the vicious cycle $[12,14,15]$. The systemic inflammation secondary to overproduction of these mediators is linked to an increased risk of atherosclerosis, as well as CV morbidity and mortality $[1,4,15]$.

Table 3. Univariate and multivariate analysis of determinants of angiogenic markers

\begin{tabular}{|c|c|c|c|c|c|c|c|c|c|}
\hline \multirow{2}{*}{$\begin{array}{c}\text { Dependent } \\
\text { variable }\end{array}$} & \multirow{2}{*}{$\begin{array}{c}\text { Independent } \\
\text { variable }\end{array}$} & \multicolumn{4}{|c|}{ Univariate analysis } & \multicolumn{4}{|c|}{ Multivariate analysis } \\
\hline & & B & CI 95\% & $\beta$ & p & B & CI 95\% & $\beta$ & p \\
\hline PDGF-BB-0 & IMT-0 & 31595.1 & $8346.4-54843.8$ & 0.459 & 0.009 & & & & \\
\hline \multirow[t]{2}{*}{ PDGF-BB-12 } & disease duration & 4612.8 & $3067.9-6157.7$ & 0.436 & 0.014 & & & & \\
\hline & $\begin{array}{l}\text { smoking } \\
\text { (current) }\end{array}$ & 3866.5 & $1179.8-6553.3$ & 0.480 & 0.006 & 3866.5 & $1179.8-6553.3$ & 0.480 & 0.006 \\
\hline Ang1-0 & CRP-0 & 1.423 & $0.064-2.781$ & 0.370 & 0.041 & & & & \\
\hline \multirow[t]{3}{*}{ Ang2-0 } & disease duration & 85.5 & $36.9-134.2$ & 0.555 & 0.001 & 87.1 & $43.9-130.3$ & 0.569 & $<0.001$ \\
\hline & $\begin{array}{l}\text { CV disease } \\
\text { (history) }\end{array}$ & 1121.3 & $102.9-2139.7$ & 0.386 & 0.032 & & & & \\
\hline & CRP-0 & 47.7 & $8.5-85.8$ & 0.419 & 0.019 & 49.2 & $17.2-81.2$ & 0.435 & 0.004 \\
\hline \multirow[t]{3}{*}{ Ang2-12 } & disease duration & 58.3 & $14.6-102.0$ & 0.452 & 0.011 & 59.9 & $20.9-98.9$ & 0.471 & 0.004 \\
\hline & CRP-0 & 38.6 & $5.6-71.6$ & 0.406 & 0.023 & & & & \\
\hline & CRP-12 & 68.9 & $10.8-127.0$ & 0.411 & 0.022 & & & & \\
\hline \multirow[t]{3}{*}{ TSP1-0 } & disease duration & 4.629 & $-0.05-9.309$ & 0.688 & 0.002 & 4.538 & $0.571-8.506$ & 0.433 & 0.028 \\
\hline & CEP-O & 4.341 & $1.358-7.323$ & 0.625 & 0.007 & 4.776 & $2.150-7.401$ & 0.688 & 0.002 \\
\hline & IMT-0 & 525.0 & $75.8-974.3$ & 0.406 & 0.024 & & & & \\
\hline
\end{tabular}

See text for abbreviations and explanations. *

Table 4. Significant results of repeated measures analysis of variance test determining the effects of dependent variables on changes of angiogenic markers between baseline and 12 months

\begin{tabular}{|c|c|c|c|c|c|}
\hline Dependent variable & Disease & Effect & $\mathbf{F}$ & $\mathbf{p}$ & Partial $\eta^{2}$ \\
\hline \multirow[t]{2}{*}{ VEGF } & All patients & Treatment & 5.550 & 0.006 & 0.161 \\
\hline & AS & $\begin{array}{c}\text { Treatment } \\
\text { Treatment } x \text { Age }\end{array}$ & $\begin{array}{l}3.899 \\
3.639\end{array}$ & $\begin{array}{l}0.034 \\
0.043\end{array}$ & $\begin{array}{l}0.245 \\
0.249\end{array}$ \\
\hline \multirow[t]{3}{*}{ PDGF-BB } & All patients & $\begin{array}{c}\text { Treatment } \\
\text { Treatment x Response } \\
\text { Treatment x Age } \\
\text { Treatment x IMT }\end{array}$ & $\begin{array}{l}6.242 \\
3.981 \\
4.566 \\
5.414\end{array}$ & $\begin{array}{l}0.009 \\
0.038 \\
0.014 \\
0.014\end{array}$ & $\begin{array}{l}0.172 \\
0.121 \\
0.136 \\
0.157\end{array}$ \\
\hline & RA & Treatment & 7.231 & 0.011 & 0.298 \\
\hline & AS & $\begin{array}{l}\text { Treatment } \mathrm{x} \text { Positive } \mathrm{CV} \\
\text { history }\end{array}$ & 4.943 & 0.017 & 0.310 \\
\hline \multirow[t]{2}{*}{ Ang1 } & All patients & $\begin{array}{c}\text { Treatment } x \text { Age at diagnosis } \\
\text { Treatment } x \text { CRP } \\
\text { Treatment } x \text { Fracture }\end{array}$ & $\begin{array}{l}4.269 \\
3.608 \\
3.352\end{array}$ & $\begin{array}{l}0.013 \\
0.033 \\
0.042\end{array}$ & $\begin{array}{l}0.128 \\
0.111 \\
0.104\end{array}$ \\
\hline & AS & Treatment $\mathrm{x}$ Age at diagnosis & 5.710 & 0.010 & 0.342 \\
\hline \multirow[t]{2}{*}{ Ang2 } & All patients & Treatment & 3.427 & 0.039 & 0.103 \\
\hline & RA & Treatment $\mathrm{x}$ CEP-0 & 3.752 & 0.035 & 0.200 \\
\hline \multirow[t]{3}{*}{ TSP-1 } & All patients & $\begin{array}{l}\text { Treatment } \mathrm{x} \text { Positive } \mathrm{CV} \\
\text { history }\end{array}$ & 3.792 & 0.041 & 0.116 \\
\hline & $\mathbf{R A}$ & $\begin{array}{l}\text { Treatment x Positive CV } \\
\text { history }\end{array}$ & 3.752 & 0.035 & 0.200 \\
\hline & AS & $\begin{array}{l}\text { Treatment } \mathrm{x} \text { Positive CV } \\
\text { history }\end{array}$ & 3.610 & 0.044 & 0.247 \\
\hline
\end{tabular}

See text for abbreviations. 
TNF- $\alpha$ is known to have pro-angiogenic role and regulates capillary sprouting through VEGF, Ang1 and Ang2 and their signalling [25]. TNF- $\alpha$, as well as other pro-inflammatory cytokines have also been implicated in the pathogenesis of inflammatory atherosclerosis [4]. Previous studies suggested that anti-TNF biologics may attenuate angiogenesis $[22,23,28]$ and atherosclerosis [26,27] associated with RA and AS. In our study, we assessed whether anti-TNF therapy would alter levels of angiogenic mediators when examined 6 and 12 months after initiation of treatment. The novelty of our study relies on its complexity, as effects of biologics on angiogenic markers were evaluated in conjunction with surrogate markers of vascular pathophysiology (FMD, ccIMT, PWV), oral health and other parameters.

First, as expected, anti-TNF therapy was clinically effective in both RA and AS as indicated by significant decreases of DAS28 and BASDAI, respectively. One-year TNF blockade resulted in significantly decreased VEGF, PDGF-BB and Ang2 levels. There have been some studies showing suppression of VEGF production by anti-TNF biologics in RA and psoriatic arthritis (PsA) [28,29]. In the study of Canete et al [28], reduced synovial expression of VEGF upon infliximab therapy was accompanied by increased Ang2 expression. The seemingly controversial Ang2 changes may be since Canete et al. studied synovial expression by histochemistry and not the serum levels. We reported close correlations between VEGF and Ang2, while Ang1 seems to be VEGF-independent $[17,35]$. In addition, Ang2 may be implicated in the initiation of neovascularization [17]. Abundant Ang2 expression was found in early PsA [35]. Ang1/Ang2 ratio may change during the course of arthritis and angiogenesis: higher levels of VEGF-dependent Ang2 levels may accompany early arthritis and early vascular proliferation, while increased VEGF-independent Ang1 expression may be observed in the later vessel maturation stage $[17,35]$. Indeed, we investigated arthritis patients with high degree of disease activity, which may have been associated with active synovial angiogenesis. Anti-TNF therapy suppressed both VEGF and Ang2 in parallel. We have not found any reports on the possible effects of anti-TNF therapy on PDGF-BB or TSP-1 in arthritis.

In addition to demonstrating the effects of biologics on angiogenic markers, we wished to correlate the levels of these markers with indicators of vascular pathophysiology, atherosclerosis, oral health and some other parameters. First, Ang2 levels correlated with the history of $\mathrm{CV}$ disease supporting the involvement of neovascularization in inflammatory atherosclerosis [14,36]. Ang2 and PDGF-BB correlated with disease duration and Ang1 and Ang2 with CRP showing that arthritis in our patients with relative long disease duration and high degree of inflammation is accompanied by active angiogenesis [13,37]. Hashimoto et al. [37] found correlations between arthritic disease activity and the levels of some angiogenic growth factors. Kurosaka, et al. [38] suggested that serum VEGF level was an RA activity marker, as well as a prognostic factor regarding joint destruction; Ang1 level may be useful as an index of sustained arthritis, while Ang2 level may reflect a state of marked angiogenesis. Moreover, our findings indicating that baseline Ang2 correlated with post-treatment CRP and, vice versa, 12-month Ang2 also correlated with baseline CRP demonstrates the continuous interplay between systemic inflammation and angiogenesis throughout the observation period.

The baseline levels of anti-CCP and anti-CEP ACPA antibodies also correlated with TSP-1 suggesting a possible link between autoimmunity and neovascularization. We have not found many studies on the possible associations between angiogenesis and ACPA in RA. Similarly to us, Eker, et al. [39] found no associations between VEGF levels and anti-
CCP status. While periodontitis and anti-CEP have been implicated in arthritides $[30,40]$, there have been no reports on possible links between angiogenesis and periodontitis or anti-CEP in arthritis. While anti-CEP correlated with TSP-1, none of the studied angiogenic factors showed association with current clinical periodontitis or tooth loss.

Baseline PDGF-BB and TSP-1 also correlated with ccIMT indicating the associations of these angiogenic markers with atherosclerosis. In the RM-ANOVA analysis, anti-TNF treatment and ccIMT determined 12-month changes in PDGF-BB, while treatment and positive CV history exerted a combined effect of changes in PDGF-BB and TSP1. Indeed, as described above, angiogenesis has been implicated in the pathogenesis of atherosclerosis [24, 36,41]. PDGF-BB and TSP-1 have been implicated in vascular smooth muscle cell proliferation and migration, as well as several other mechanisms underlying atherosclerosis $[20,42,43]$. Yet, we have not found any reports with respect to the direct involvement of these angiogenic factors in arthritisassociated atherogenesis.

Smoking has been implicated in the pathogenesis of arthritides, as well as atherosclerosis and CV disease [44-46]. In our multivariate analysis, PDGF-BB levels after one-year biological therapy were significantly higher in smokers versus non-smokers. Interestingly, the direct association of smoking with inflammatory angiogenesis has not yet been evaluated. However, PDGF signalling has been implicated in cigarette smoke-induced pulmonary hypertension [47].

\section{Conclusion}

In conclusion, we and others have previously reported that angiogenesis is implicated in arthritides, as well as inflammatory (accelerated) atherosclerosis. The levels of some angiogenic markers correlate with disease duration, CRP, RA-related autoantibodies and carotid atherosclerosis. One-year anti-TNF therapy attenuated the production of some angiogenic markers in both RA and AS. Thus, some angiogenic mediators may be used as surrogate biomarkers that reflect the interplay of angiogenesis, inflammation and atherosclerosis in arthritides.

\section{Declarations}

\section{Ethics approval and consent to participate}

The study was approved by the Hungarian Scientific Research Council Ethical Committee (approval No. 14804-2/2011/EKU). Written informed consent was obtained from each patient and assessments were carried out according to the Declaration of Helsinki. No individual patient data are reported.

\section{Consent for publication}

No individual patient data are reported. Therefor this consent is Not Applicable.

\section{Availability of data and material}

The datasets used and analyzed during the current study are available from the corresponding author upon reasonable request.

\section{Competing interest}

None of the authors have any competing interests.

\section{Funding}

This research was supported by the European Union and the State of Hungary and co-financed by the European Social 
Fund in the framework of TAMOP-4.2.4.A/2-11/1-2012-0001 'National Excellence Program '(Z.S.); by the European Union grants GINOP-2.3.2-15-2016-00015 and GINOP-2.3.2-15-2016-00050 (Z.S.); and by the Pfizer Investigator Initiated Research Grant No. WS1695414 (Z.S.).

\section{Authors' contributions}

All authors have read and approved the manuscript. This is ensured.

EB: study concept, patient recruitment, patient examination, data collection, manuscript preparation

EV: patient recruitment, patient examination, data collection

GK: patient examination, vascular assessments, data collection

AP: blood sample handling, biobanking, laboratory assessments, data collection

AH: blood sample handling, biobanking, laboratory assessments, data collection

KH: data collection, statistical analysis

SS (Szamosi): patient recruitment, patient examination, data collection

AV: patient recruitment, patient examination, data collection

PC: blood sample handling, laboratory analysis

LB: patient recruitment, patient examination, data collection

LP: patient examination, data collection

FB: patient examination, data collection

JM: angiogenesis data handling, data collection

MB: angiogenesis data handling, data collection

IT: assessment of periodontal status, data collection, manuscript preparation

KL: anti-CEP assessments, data collection and handling

NK: anti-CEP assessments, data collection and handling

SS (Szanto): study concept, patient recruitment, patient examination, data collection, manuscript preparation

GS: study concept, patient recruitment, patient examination, data collection, manuscript preparation

$\mathrm{ZN}$ : data collection, statistical analysis

UF: angiogenesis data handling, data collection

DJV: angiogenesis data handling, data collection, manuscript preparation

ZS: principal investigator, study concept, data analysis, manuscript preparation

\section{Acknowledgements}

Funding described above. Otherwise Not Applicable.

\section{References}

1. Agca R, Heslinga SC, Rollefstad S, Heslinga M, McInnes IB3, et al. (2017) EULAR recommendations for cardiovascular disease risk management in patients with rheumatoid arthritis and other forms of inflammatory joint disorders: 2015/2016 update. Ann Rheum Dis 76: 17-28. [Crossref]
2. Bodnar N, Kerekes G, Seres I, Paragh G, Kappelmayer J, et al. (2011) Assessment of subclinical vascular disease associated with ankylosing spondylitis. J Rheumatol 38 : 723-729. [Crossref]

3. González-Gay MA, Szekanecz Z, Popa CD, Dessein P (2012) Atherosclerosis in rheumatoid arthritis. Mediators Inflamm 2012: 489608. [Crossref]

4. Choy E, Ganeshalingam K, Semb AG, Szekanecz Z, Nurmohamed M (2014) Cardiovascular risk in rheumatoid arthritis: recent advances in the understanding of the pivotal role of inflammation, risk predictors and the impact of treatment. Rheumatology 53: 2143-2154. [Crossref]

5. Kerekes G, Soltesz P, Nurmohamed MT, Gonzalez-Gay MA, Turiel M, et al. (2012) Validated methods for assessment of subclinical atherosclerosis in rheumatology. Nat Rev Rheumatol 8: 224-234. [Crossref]

6. Soltesz P, Der H, Kerekes G, Szodoray P, Szucs G, et al. (2009) A comparative study of arterial stiffness, flow-mediated vasodilation of the brachial artery, and the thickness of the carotid artery intima-media in patients with systemic autoimmune diseases. Clin Rheumatol 28: 655-662. [Crossref]

7. Corretti MC, Anderson TJ, Benjamin EJ, Celermajer D, Charbonneau F, et al. (2002) Guidelines for the ultrasound assessment of endothelial-dependent flow-mediated vasodilation of the brachial artery: a report of the International Brachial Artery Reactivity Task Force. J Am Coll Cardiol 39: 257-265. [Crossref]

8. Kanters SD, Algra A, van Leeuwen MS, Banga JD (1997) Reproducibility of in vivo carotid intima-media thickness measurements: a review. Stroke 28: 665-671. [Crossref]

9. Baulmann J, Schillings U, Rickert S, Uen S, Dusing R, et al. (2008) A new oscillometric method for assessment of arterial stiffness: comparison with tonometric and piezoelectronic methods. J Hypertens 26: 523-528. [Crossref]

10. Van Sijl AM, Peters MJ, Knol DK, de Vet HC, Gonzalez-Gay MA, Smulders YM, et al (2010) Carotid intima media thickness in rheumatoid arthritis as compared to control subjects: a meta-analysis. Semin Arthritis Rheum 40: 389-397. [Crossref]

11. Gonzalez-Juanatey C, Llorca J, Martin J, Gonzalez-Gay MA (2009) Carotid intimamedia thickness predicts the development of cardiovascular events in patients with rheumatoid arthritis. Semin Arthritis Rheum 38: 366-371. [Crossref]

12. Szekanecz Z, Koch AE (2007) Mechanisms of Disease: angiogenesis in inflammatory diseases. Nat Clin Pract Rheumatol 3: 635-643.

13. Drouart M, Saas P, Billot M, Cedoz JP, Tiberghien P, et al. (2003) High serum vascular endothelial growth factor correlates with disease activity of spondylarthropathies. Clin Exp Immunol 132: 158-162. [Crossref]

14. Folkman J (1995) Angiogenesis in cancer, vascular, rheumatoid and other disease. Nat Med 1: 27-31. [Crossref]

15. Balogh E, Pusztai A, Hamar A, Végh E, Szamosi S, et al. (2019) Autoimmune and angiogenic biomarkers in autoimmune atherosclerosis. Clin Immunol 199: 47-51. [Crossref]

16. Tas SW, Maracle CX, Balogh E, Szekanecz Z (2016) Targeting of proangiogenic signalling pathways in chronic inflammation. Nat Rev Rheumatol 12: 111-122. [Crossref]

17. Asahara T, Chen D, Takahashi T, Fujikawa K, Kearney M, et al. (1998) Tie2 receptor ligands, angiopoietin-1 and angiopoietin-2, modulate VEGF-induced postnatal neovascularization. Circ Res 83: 233-240. [Crossref]

18. Kiselyov A, Balakin KV, Tkachenko SE (2007) VEGF/VEGFR signalling as a target for inhibiting angiogenesis. Expert Opin Investig Drugs 16: 83-107. [Crossref]

19. Koch AE, Szekanecz Z, Friedman J, Haines GK, Langman CB, et al. (1998) Effects of thrombospondin-1 on disease course and angiogenesis in rat adjuvant-induced arthritis. Clin Immunol Immunopathol 86: 199-208. [Crossref]

20. Maier KG, Ruhle B, Stein JJ, Gentile KL, Middleton FA, et al. (2016) Thrombospondin-1 differentially regulates microRNAs in vascular smooth muscle cells. Mol Cell Biochem 412: 111-117. [Crossref]

21. Misra S, Mondal S, Chatterjee S, Guin A, Sinhamahapatra P, et al. (2018) Association of Angiogenic and Inflammatory Markers with Power Doppler Ultrasound Vascularity Grade and DAS28-CRP in Early Rheumatoid Arthritis: A Comparative Analysis. Biomed Res Int 2018: 6906374. [Crossref]

22. Veale DJ, Fearon U (2006) Inhibition of angiogenic pathways in rheumatoid arthritis: potential for therapeutic targeting. Best Pract Res Clin Rheumatol 20: 941-947. [Crossref]

23. Szekanecz Z, Koch AE (2008) Targeting Angiogenesis in Rheumatoid Arthritis. Curr Rheumatol Rev 4: 298-303. [Crossref] 
24. Winter PM, Morawski AM, Caruthers SD, Fuhrhop RW, Zhang H, et al (2003) Molecular imaging of angiogenesis in early-stage atherosclerosis with alpha(v)beta3integrin-targeted nanoparticles. Circulation 108: 2270-2274. [Crossref]

25. Leibovich SJ, Polverini PJ, Shepard HM, Wiseman DM, Shively V, et al. (1987) Macrophage-induced angiogenesis is mediated by tumour necrosis factor-alpha. Nature 329: 630-632. [Crossref]

26. Greenberg JD, Kremer JM, Curtis JR, Hochberg MC, Reed G, et al. (2011)Tumour necrosis factor antagonist use and associated risk reduction of cardiovascular events among patients with rheumatoid arthritis. Ann Rheum Dis 70: 576-582. [Crossref]

27. Szekanecz Z, Kerekes G, Soltész P (2009) Vascular effects of biologic agents in RA and spondyloarthropathies. Nat Rev Rheumatol 5: 677-684. [Crossref]

28. Canete JD, Pablos JL, Sanmarti R, Mallofre C, Marsal S, et al. (2004) Antiangiogenic effects of anti-tumor necrosis factor alpha therapy with infliximab in psoriatic arthritis. Arthritis Rheum 50:1636-1641. [Crossref]

29. Strunk J, Bundke E, Lange U (2006) Anti-TNF-alpha antibody Infliximab and glucocorticoids reduce serum vascular endothelial growth factor levels in patients with rheumatoid arthritis: a pilot study. Rheumatol Int 26: 252-256. [Crossref]

30. Lundberg K, Bengtsson C, Kharlamova N, Reed E, Jiang X, et al (2013) Genetic and environmental determinants for disease risk in subsets of rheumatoid arthritis defined by the anticitrullinated protein/peptide antibody fine specificity profile. Ann Rheum Dis 72: 652-658. [Crossref]

31. Pischon N, Pischon T, Gulmez E, Kroger J, Purucker P, et al. (2010) Periodontal disease in patients with ankylosing spondylitis. Ann Rheum Dis 69: 34-38. [Crossref]

32. Tonetti MS (2009) Periodontitis and risk for atherosclerosis: an update on intervention trials. J Clin Periodontol 36 Suppl 10: 15-19. [Crossref]

33. Tonetti MS, Greenwell H, Kornman KS (2018) Staging and grading of periodontitis: Framework and proposal of a new classification and case definition. $J$ Periodontol 89: S159-S172. [Crossref]

34. Kerekes G, Szekanecz Z, Dér H, Sándor Z, Lakos G, et al. (2008) Endothelia dysfunction and atherosclerosis in rheumatoid arthritis: a multiparametric analysis using imaging techniques and laboratory markers of inflammation and autoimmunity. $J$ Rheumatol 35: 398-406. [Crossref]

35. Fearon U, Griosios K, Fraser A, Reece R, Emery P, et al. (2003) Angiopoietins, growth factors, and vascular morphology in early arthritis. J Rheumatol 30: 260-268. [Crossref]
36. Balogh E, Pusztai A, Hamar A, Végh E, Szamosi S, et al. (2019) Autoimmune and angiogenic biomarkers in autoimmune atherosclerosis. Clin Immunol 199: 47-51. [Crossref]

37. Hashimoto N, Iwasaki T, Kitano M, Ogata A, Hamano T (2003) Levels of vascular endothelial growth factor and hepatocyte growth factor in sera of patients with rheumatic diseases. Mod Rheumatol 13: 129-134. [Crossref]

38. Kurosaka D, Hirai K, Nishioka M, Miyamoto Y, Yoshida K, et al. (2010) Clinica significance of serum levels of vascular endothelial growth factor, angiopoietin-1, and angiopoietin-2 in patients with rheumatoid arthritis. $J$ Rheumatol 37: 1121-1128 [Crossref]

39. Eker YÃ, Pamuk Ã, Pamuk GE, DÃ nmez S, ÃłakÄ $\pm r$ N (2014) The Frequency of anti-CCP antibodies in patients with rheumatoid arthritis and psoriatic arthritis and their relationship with clinical features and parameters of angiogenesis: A comparative study. Eur J Rheumatol 1: 67-71. [Crossref]

40. Lundberg K, Wegner N, Yucel-Lindberg T, Venables PJ (2010) Periodontitis in RA-the citrullinated enolase connection. Nat Rev Rheumatol 6: 727-730. [Crossref]

41. Perrotta I1 (2013) Ultrastructural features of human atherosclerosis. Ultrastruct Pathol 37: 43-51. [Crossref]

42. Dong X1, Hu H2, Fang Z3, Cui J4, Liu F5 (2018) CTRP6 inhibits PDGF-BB-induced vascular smooth muscle cell proliferation and migration. Biomed Pharmacother 103: 844-850. [Crossref]

43. Andrae J, Gallini R, Betsholtz C (2008) Role of platelet-derived growth factors in physiology and medicine. Genes Dev 22: 1276-1312. [Crossref]

44. Klareskog L, Padyukov L, Alfredsson L (2007) Smoking as a trigger for inflammatory rheumatic diseases. Curr Opin Rheumatol 19: 49-54. [Crossref]

45. Gerli R, Sherer Y, Vaudo G, Schillaci G, Gilburd B, et al. (2005) Early atherosclerosis in rheumatoid arthritis: effects of smoking on thickness of the carotid artery intima media. Ann N Y Acad Sci 1051:281-290. [Crossref]

46. Szodoray P, Szabo Z, Kapitany A, Gyetvai A, Lakos G, et al. (2010) Anti-citrullinated protein/peptide autoantibodies in association with genetic and environmental factors as indicators of disease outcome in rheumatoid arthritis. Autoimmun Rev 9: 140-143. [Crossref]

47. Xing AP, Hu XY, Shi YW, Du YC (2012) Implication of PDGF signaling in cigarette smoke-induced pulmonary arterial hypertension in rat. Inhalation toxicology 24: 468475. [Crossref]

Copyright: (C2019 Balogh E. This is an open-access article distributed under the terms of the Creative Commons Attribution License, which permits unrestricted use, distribution, and reproduction in any medium, provided the original author and source are credited. 